\title{
A 3D Dynamic Lumped Parameter Thermal Network of Air-Cooled YASA Axial Flux Permanent Magnet Synchronous Machine
}

\author{
Abdalla Hussein Mohamed ${ }^{1,2,3, *}$, Ahmed Hemeida ${ }^{3,4}$, Alireza Rashekh ${ }^{5}$ (D), \\ Hendrik Vansompel ${ }^{1,2}$ (D), Antero Arkkio ${ }^{4}$ and Peter Sergeant 1,2 (D) \\ 1 Department of Electrical Machines, Metals, Mechanical Constructions and Systems, Ghent University, \\ 9052 Ghent, Belgium; Hendrik.Vansompel@UGent.be (H.V.); Peter.Sergeant@UGent.be (P.S.) \\ 2 EEDT, Flanders Make, the Research Centre for the Manufacturing Industry, B-8500 Kortrijk, Belgium \\ 3 Department of Electrical Power and Machines, Cairo University, Giza 12613, Egypt; a.hemeida@live.com \\ 4 Aalto University, Department of Electrical Engineering and Automation, P.O. Box 13000, \\ FI-00076 Espoo, Finland; Antero.arkkio@aalto.fi \\ 5 Department of Flow, Heat and Combustion Mechanics, Faculty of Engineering and Architecture, \\ Ghent University, B-9000 Ghent, Belgium; Alireza.Rasekh@UGent.be \\ * Correspondence: a.hussien.rashad@gmail.com; Tel.: +3-246-582-7320
}

Received: 8 March 2018; Accepted: 26 March 2018; Published: 28 March 2018

\begin{abstract}
To find the temperature rise for high power density yokeless and segmented armature (YASA) axial flux permanent magnet synchronous (AFPMSM) machines quickly and accurately, a 3D lumped parameter thermal model is developed and validated experimentally and by finite element (FE) simulations on a $4 \mathrm{~kW}$ YASA machine. Additionally, to get insight in the thermal transient response of the machine, the model accounts for the thermal capacitance of different machine components. The model considers the stator, bearing, and windage losses, as well as eddy current losses in the magnets on the rotors. The new contribution of this work is that the thermal model takes cooling via air channels between the magnets on the rotor discs into account. The model is parametrized with respect to the permanent magnet (PM) angle ratio, the PM thickness ratio, the air gap length, and the rotor speed. The effect of the channels is incorporated via convection equations based on many computational fluid dynamics (CFD) computations. The model accuracy is validated at different values of parameters by FE simulations in both transient and steady state. The model takes less than $1 \mathrm{~s}$ to solve for the temperature distribution.
\end{abstract}

Keywords: YASA; AFPMSM; LPTN; thermal model; axial flux machines; FEM

\section{Introduction}

YASA (yokeless and segmented armature) axial flux permanent magnet synchronous machines (AFPMSMs) have been providing challenging opportunities for industries for several years. Thanks to the absence of the yoke in the YASA type (shown in Figure 1a), it provides the highest power density and efficiency compared to other AFPMSM types, such as the toroidally wound internal stator (TORUS)-type machine shown in Figure $1 \mathrm{~b}$ and the axial flux internal rotor (AFIR)-type machine shown in Figure 1c [1].

The proper design of this machine requires the development of accurate and fast models of the YASA machine. These include electromagnetic, mechanical, and thermal models for the machine. Therefore, accurate and fast models have been developed. Electromagnetic 3D finite element (FE) models are the most accurate but the most time consuming. Two-dimensional (2D) multi-layer FE models in [2,3] provide an alternative to the 3D FE models. However, they are still very 
time-consuming. Therefore, fast and accurate analytical models were developed in [4-7]. These models are capable of calculating all the electromagnetic quantities (cogging torque, torque ripple, iron losses, permanent magnet (PM) losses, inductances, and no load and full load voltages) in a very efficient way. Authors in $[8,9]$ developed mechanical analytical models for the YASA machine for a proper structural analysis of the rotor and stator for large-scale applications. In addition, the authors in [10] developed mechanical FE models for a coreless AFPMSM in a high-speed application.

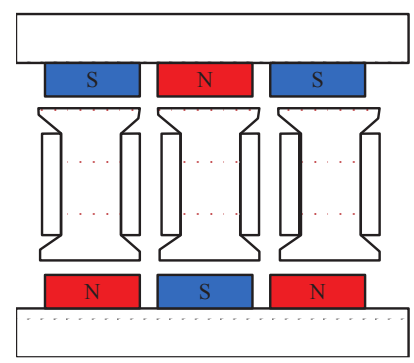

(a)

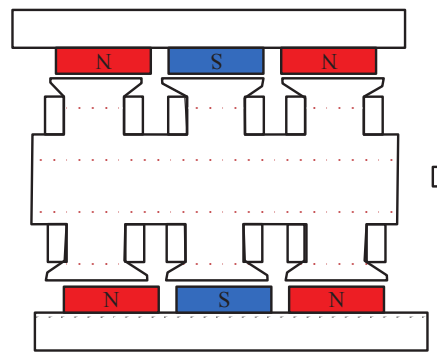

(b)

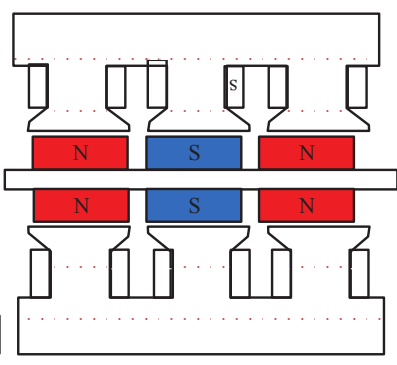

(c)

Figure 1. Different topologies of the axial flux permanent magnet synchronous machines (AFPMSMs) (a) YASA (yokeless and segmented armature); (b) TORUS (toroidally wound internal stator); (c) AFIR (axial flux internal rotor) [11].

Thermal modeling of the YASA machine is an important aspect in the design procedure. One of the most important incentives to study the thermal behaviour of electrical machines (including the YASA machine) is that the maximum torque capability of the machine depends on the maximum current density that can be reached before winding insulation failure or permanent magnets demagnetization [12]. There are two types of modelling to obtain the temperature distribution inside the machine. The first type is a coupled computational fluid dynamics (CFD) and thermal FE simulation, such as in [13-16]. The second type does not use CFD, and is based on appropriate equations for the convective heat coefficients, as proposed in [17-20]. These coefficients can be the source inputs to a more detailed 3D FE thermal model [21] or a lumped parameter thermal network (LPTN) [22,23].

Coupled thermal and CFD analysis is highly needed with complex cooling systems. The authors in [13] studied the thermal effect of a forced air cooling using two different fan types mounted on the shaft in addition to the cooling fins mounted on the stator surface. The authors compared the cooling without fans and with fans. They proved the great capability of the thermal model to describe the temperature behaviour of the system. Additionally, Ref. [14,15] presented coupled FE and CFD analysis for studying cooling systems in electrical machines. The method was proven to be accurate. However, for the methods with coupled FE and CFD models, the computational effort is very high.

The authors in $[17,18]$ studied the heat flow for two solid discs, in which one disc is rotating by a certain speed but the geometry is too simple for a real YASA machine. To study the air flow and heat flow in the airgaps of the YASA machine in more detail, the authors in [19] included the PMs on the rotor surface and developed analytical equations for the heat flow on the boundary surfaces taking into account the air flow inside the channels between the PMs. However, the model is not yet a complete motor model, because the solid parts of rotor and stator are not modelled.

In [21], the authors used convection coefficients of a simple geometry (rotating solid discs) using $3 \mathrm{D}$ finite element method (FEM) to predict the temperature in a YASA motor. However, this FEM-based model is quite slow and does not tackle complex fan-shaped magnets.

The literature lacks a full LPTN that describes the thermal behaviour of a YASA motor with innovative cooling via air channels between magnets. In this paper, the authors developed such an LPTN based on the convective heat coefficients developed in $[18,19]$. The model is validated by FEM simulations and by experiments. Additionally, the effect of air gap length, rotor speed, and geometrical parameters of the magnet on the machine temperature is investigated by the FEM and LPTN model. 


\section{AFPMSM Lumped Parameter Thermal Modeling}

This paper develops a fast parametrized 3D thermal model by coupling a separate LPTN of the stator and rotor through the introduction of the analytical convective heat transfer coefficients in $[18,19]$. The model considers a rotor shape with holes. These holes form air channels, providing an innovative and effective way of cooling. All power losses occurring in the YASA machine are explained in Section 2.1 and are taken into account in the LPTN model. Figure 2 is a cross-section of the whole YASA machine, along with the studied rotor geometry. The stator consists of concentrated windings wound around laminated cores. The teeth are distributed around the stator circumference and housed inside a laminated aluminum housing. The two rotors are composed of a steel disc with permanent magnets mounted on the surface.

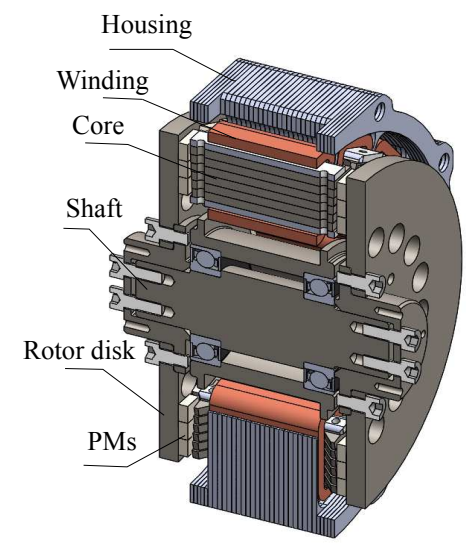

(a)

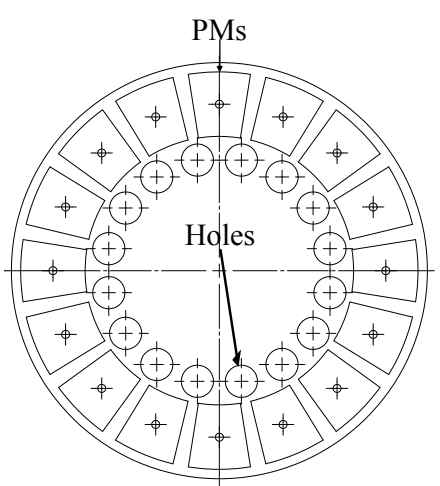

(b)

Figure 2. Prototype and rotor structure: (a) Prototype cross-section; (b) Rotor geometry. PM: permanent magnet.

Due to both the symmetry of stator and rotor construction and the thermal periodicity, only one quarter of one stator tooth and one rotor magnet pole part need to be modeled. Figure 3 shows the modeled parts of the stator and rotor.

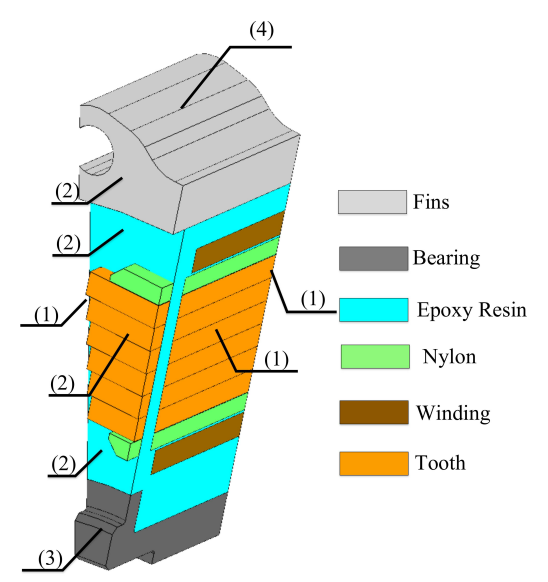

(a)

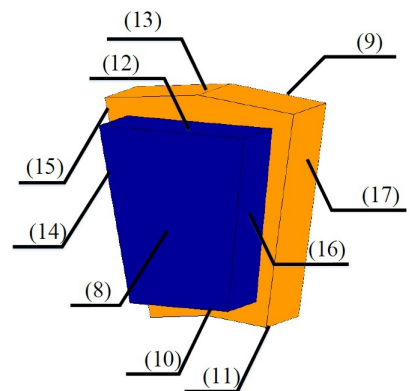

(b)

Figure 3. Stator and rotor modeled parts: (a) One quarter of the stator tooth: (1) thermal insulation; (2) stator facing rotor upper part; (3) stator facing rotor lower part; (4) stator side wall. (b) Modeled rotor part:(8) rotor facing stator upper; (9) rotor left side; (10) PM lower; (11) rotor lower; (12) PM upper; (13) rotor upper; (14) PM left; (15) PM right; (16) rotor facing stator. 


\subsection{YASA Machine Power Losses}

Different electrical, magnetic, and mechanical power loss mechanisms take place in the YASA axial flux machine. These losses occur in the winding, stator core, permanent magnets, and bearings, causing a temperature increase in different machine parts. These losses are modeled by heat sources in the LPTN model. The accuracy of the predicted temperature depends on the accuracy of the power losses calculation.

\subsubsection{Copper Losses}

Copper losses $Q_{w d g}$ are calculated using the formulas in [4]. The modeled winding is divided into three regions: the effective copper winding with power loss $P_{w d g}$, upper end winding with power loss $P_{\text {endup }}$, and lower end winding with power loss $P_{\text {enddown }}$. The copper losses are distributed between these regions according to their respective volumes, assuming that the copper losses are equally distributed over the volume. Equation (1) governs the sum of the three losses parts:

$$
P_{\text {endup }}+P_{\text {enddown }}+P_{\text {wdg }}=Q_{w d g} / 4 / N_{s}
$$

where $N_{S}$ is the number of teeth.

\subsubsection{Core Losses}

Core losses $Q_{\text {iron }}$ are calculated using formulas in [4]. They are divided into two parts (inside the tooth $P_{s t}$ and the tooth tips $P_{s t_{\text {tips }}}$ ) their sum is expressed by Equation (2). The core losses are also assumed to be uniformly distributed over the volume.

$$
P_{s t}+P_{s t_{t i p s}}=Q_{i r o n} / 4 / N_{s}
$$

\subsubsection{Permanent Magnet Losses}

Some losses take place in the PMs due to induced eddy currents. These losses $Q_{P M}$ are calculated in [6]. The PM losses in one segment of the rotor equal

$$
P_{P M}=Q_{P M} / 2 / N_{m}
$$

where $N_{m}$ is the number of PMs in one rotor disk.

\subsubsection{Mechanical Losses}

The aerodynamic forces acting on rotary parts of the machine cause mechanical losses in the surfaces exposed to it. Extensive CFD simulations and curve fittings done in [24] have found accurate and parametrized formulas for the windage losses on every surface. These formulas are used to calculate the mechanical losses.

The equations take the form:

$$
\begin{aligned}
& P_{f, v}^{\prime}=P_{f, v}^{\prime *} \times Z_{f, 2}(R e) \times Z_{f, 3}\left(\alpha_{m}\right) \times Z_{f, 4}(L), \\
& P_{f, p}^{\prime}=P_{f, p}^{\prime *} \times X_{f, 2}(R e) \times X_{f, 3}\left(\alpha_{m}\right) \times X_{f, 4}(L),
\end{aligned}
$$

where $P_{f, v}^{\prime}$ and $P_{f, p}^{\prime}$ are the windage losses for surface $f$ due to viscous forces and pressure forces, respectively. $P_{f, v}^{\prime *}, P_{f, p}^{\prime *}$ are the windage losses at the reference point. The following parameters are important because they influence air flow in the machine and thus the thermal behaviour: $G$ is the gap size ratio (Equation (5)), $R e$ is the rotational Reynolds number (Equation (5)), $\alpha_{m}$ is the magnet angle ratio (Equation (6)), and $L$ is the magnet thickness ratio (Equation (6)). $Z, X$ are the fitting functions developed for every surface. 


$$
\begin{gathered}
G=\frac{2 s}{D}, \operatorname{Re}=\frac{\Omega D^{2}}{4 v}, \\
\alpha_{m}=\alpha \times N_{m} / 360, \\
L=\frac{t}{R},
\end{gathered}
$$

where $\Omega$ is the rotational speed in $\mathrm{rad} / \mathrm{s}, D$ is the outer diameter, $v$ is the kinematic viscosity of air, $s$ is the air gap thickness, $\alpha$ is the magnet angle, $t$ is the magnet thickness shown in Figure 4 , and $R$ is the rotor outer radius.

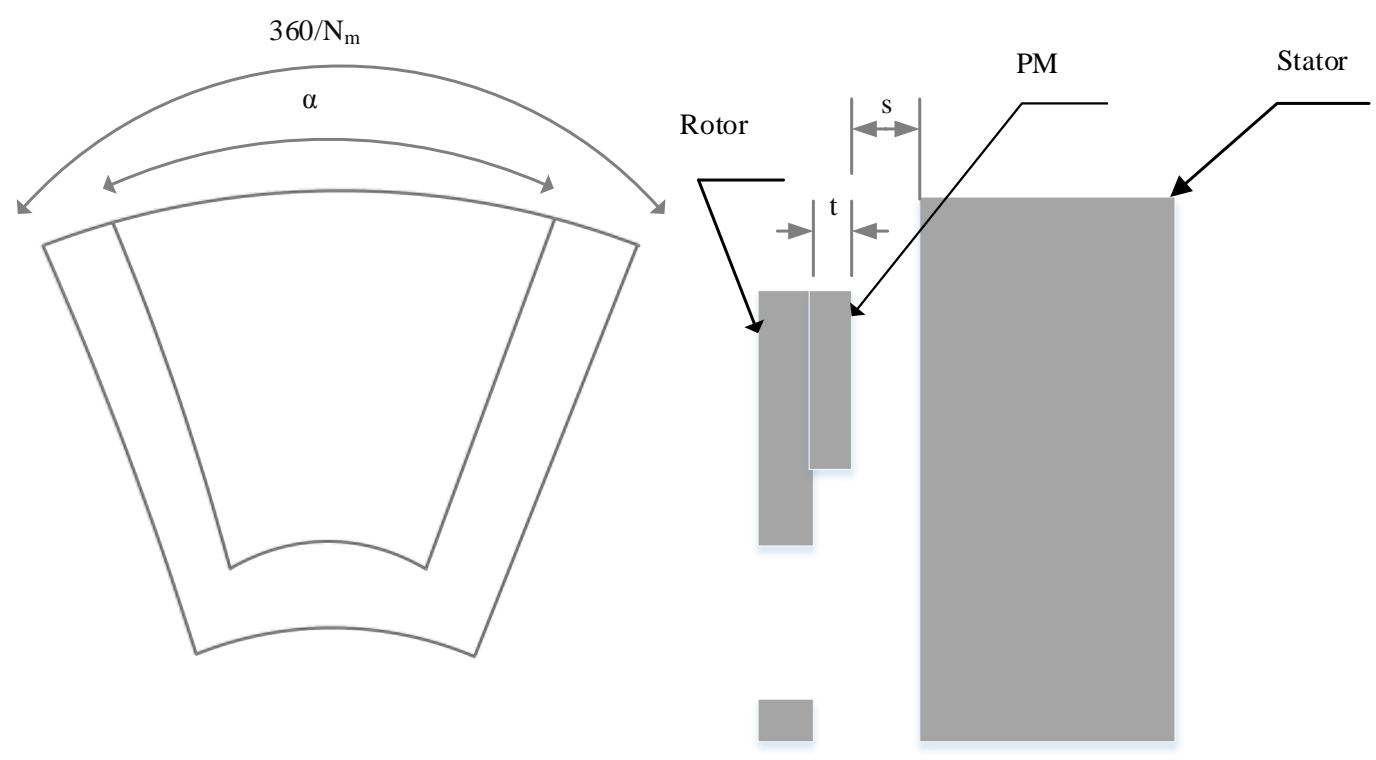

Figure 4. Surfaces of the rotor-stator system.

From Equation (4), the mechanical losses depend on the precise shape of the magnets and cooling channels.

\subsection{Modeling of Convection Heat Transfer}

The heat flux $\bar{q}_{i}$ on each boundary surface $i$ exposed to convective heat transfer according to Figure 3 for both stator and rotor is defined by Equation (7) [21]. These surfaces are: stator housing outer surface, stator tooth facing rotor, rotor magnet facing stator, magnet upper part, rotor back iron facing stator, rotor back iron upper part, and rotor disc back.

$$
\bar{q}_{i}=\bar{h}_{i}\left(\bar{T}_{\text {surf }}-\bar{T}_{r e f_{i}}\right)
$$

where $\bar{h}_{i}$ is the average convection heat transfer coefficient at surface $i, \bar{T}_{\text {surf }}$ is the surface temperature, and $\bar{T}_{r e f_{i}}$ is the reference temperature (average temperature of a nearby fluid contained within an adjacent volume $i$ ).

The reference temperature and the convective heat transfer coefficient are both found in $[18,19]$. The reference temperature depends on the rotor and stator temperatures, and also on the parameters $a_{i}$ and $b_{i}$ :

$$
\bar{T}_{r e f_{i}}=a_{i} T_{r}+b_{i} T_{s}+\left(1-\left(a_{i}+b_{i}\right)\right) T_{a},
$$

where $T_{r}$ is the rotor temperature, $T_{s}$ is the stator temperature, and $T_{a}$ is the ambient temperature.

The convection coefficients $\bar{h}_{i}$ besides $a_{i}$ and $b_{i}$ are dependent on the gap size ratio $(G)$ and the rotational Reynolds number $(R e)[18,19]$. 
The convection coefficient is also a function of the Nusselt number for each surface $i$ :

$$
\overline{h_{i}}=\frac{N u_{i} k}{l_{i}},
$$

where $k$ is the thermal conductivity of air, and $l_{i}$ is the characteristic length.

The $N u_{i}, a_{i}$, and $b_{i}$ are functions of the gap size ratio and the Reynolds number. In addition to these parameters, they are also functions of the permanent magnet (PM) span ratio $\alpha_{m}$ and the PM thickness ratio $L$ for this studied rotor type.

$$
\left.\begin{array}{rl}
a_{h_{i}} & =F_{h_{i}}\left(G, R e, \alpha_{m}, L\right) \\
b_{h_{i}} & =G_{h_{i}}\left(G, R e, \alpha_{m}, L\right) \\
N \bar{u}_{h_{i}} & =Y_{h_{i}}\left(G, \operatorname{Re}, \alpha_{m}, L\right)
\end{array}\right\} \text { With Hollow Cylinder. }
$$

The reference temperature is introduced in the model as a temperature source of the air near every convected surface. The convection heat transfer coefficient is used in the calculation of the thermal resistance between the air and the surface.

For surfaces with convection, the equivalent thermal resistance $R_{c}$ at this surface is

$$
R_{c}=\frac{1}{A_{c} h_{i}},
$$

where $A_{c}$ is the area exposed to the convection and $h_{i}$ is the convection coefficient for surface $i$ computed by Equation (9).

\subsection{Lumped Parameter Thermal Network}

The LPTN is a network of thermal resistors, thermal capacitors, and heat sources connected together according to the heat flow directions and the positions of thermal nodes inside the machine. Both stator and rotor modeled segments are divided into thermal nodes, from which the heat is conducted in the axial, radial, and circumferential directions. Figure $5 \mathrm{a}$ is a differential representation of each modeled node in both machine segments. When there is a heat generation in the node, it is represented by the model shown in Figure $5 b$. Figure $5 c$ presents the equivalent model for an element without heat generation.

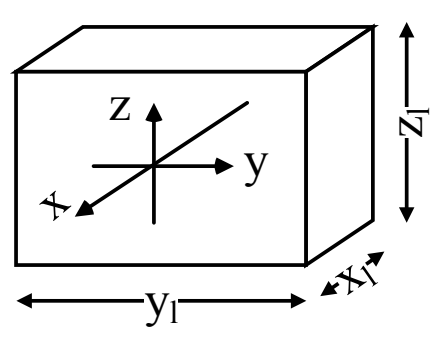

(a)

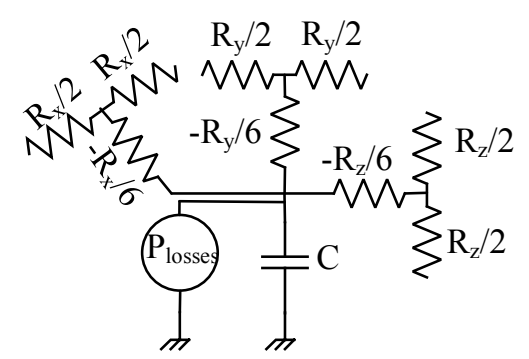

(b)

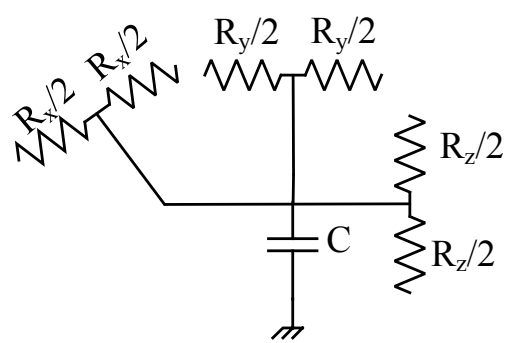

(c)

Figure 5. Node network representation. (a) Block orientation; (b) Resistance model with heat source; (c) Resistance model without heat source.

The central node connected to the capacitance $(C)$ gives the mean temperature of the element. The mean temperature of the three-dimensional axis $(x, y, z)$ gives a lower temperature than the central node. Therefore, a negative resistance equal to $-1 / 6$ of the total resistance in each direction is presented to account for this effect. This resistance comes from the independent solution of the heat conduction equation, as explained in $[25,26]$. 
The differential resistance in each direction $(x, y, z)$ can be calculated by Equation (12). Detailed methods for the calculation of the thermal resistances can be found in [27].

$$
d R_{x}=\frac{d x_{l}}{d A_{x} K_{x}}, d R_{y}=\frac{d y_{l}}{d A_{y} K_{y}}, d R_{z}=\frac{d z_{l}}{d A_{z} K_{z}},
$$

where $d R_{x}, d R_{y}, d R_{z}$ are the thermal resistances in the $x, y, z$ directions. $d x_{l}, d y_{l}, d z_{l}$ are the lengths of the element. $d A_{x}, d A_{y}, d A_{z}$ are the areas perpendicular to the heat flow. $K_{x}, K_{y}, K_{z}$ are the thermal conductivities of the material.

The stator core is made of thin laminated silicon steel, while the stator housing is made of aluminum laminations. These laminations are stacked together by an epoxy resin. Additionally, the stator windings are epoxy infiltrated. The thermal conductivity of the epoxy resin is low. This directly affects the overall effective thermal conductivity of the material mix, and hence the heat conduction in the machine. This material mix is taken into account by calculating an equivalent conductivity and considering the thermal conductivity variation with respect to the heat flow direction.

For the copper winding, the equivalent thermal conductivity $K_{w}$ in the lapping direction and perpendicular to the lapping direction is calculated as:

$$
K_{w}= \begin{cases}f_{w i} k_{h c o}+\left(1-f_{w i}\right) k_{h e} & \text { in the lapping direction, } \\ k_{h e} \frac{\left(1+f_{w i}\right) k_{h c o}+f_{w i} k_{h e}}{\left(1-f_{w i}\right) k_{h c o}+\left(1+\left(1-f_{w i}\right)\right) k_{h e}} & \text { in perpendicular direction, }\end{cases}
$$

where $K_{h e}$ is the thermal conductivity of epoxy resin, $K_{h c o}$ is the thermal conductivity of the copper, and $f_{w i}$ is the winding fill factor.

The thermal conductivity for both stator core and housing material mix is also calculated using Equation (13) considering the different stacking factors and material properties [21].

The thermal resistance for each geometrical node shape is calculated by integrating Equation (12) according to the direction of heat flow and dimensions.

The thermal capacitance $C$ equals

$$
C=\rho C_{p} V,
$$

where $\rho$ is the density of the material used, $C_{p}$ is the specific heat capacitance of the material, and $V$ is the volume of the element.

In case of a material mix, the specific heat capacitance $C_{p}$ and the mass density $\rho$ are calculated using

$$
\begin{gathered}
C_{p_{m}}=f_{\text {wors }} C_{p_{1}}+\left(1-f_{\text {wors }}\right) C_{p_{2}}, \\
\rho_{m}=f_{\text {wors }} \rho_{1}+\left(1-f_{\text {wors }}\right) \rho_{2},
\end{gathered}
$$

where $C_{p_{m}}$ is the specific heat capacity of the material mix, $f_{\text {wors }}$ is the winding or stacking factor, $C_{p_{1}}$ is the specific heat capacitance of material $1, C_{p_{2}}$ is the specific heat capacitance of material 2, $\rho_{m}$ is the mass density of the material mix, $\rho_{1}$ is the mass density of material 1 , and $\rho_{2}$ is the mass density of material 2.

The stator segment model shown in Figure 3a is divided into two regions in the axial direction. They are at the tooth tips and at the center of the machine. Both regions are shown in Figure 6. The stator is divided into 20 subregions. The model of each subregion is constructed using the method described in Section 2.3 and Figure 5. The subregions with numbers are shown in Figure 6 with the corresponding LPTN model in Figure 7.

The convection coefficients $\left(h_{c 1}, h_{c 2}, h_{c 3}\right)$ and reference temperatures $\left(T_{r e f 1}, T_{r e f 2}, T_{r e f 3}\right)$ noted in Figure 7 can be calculated using Equations (8)-(10) [18,19].

Figure 8 shows the LPTN for the rotor. 


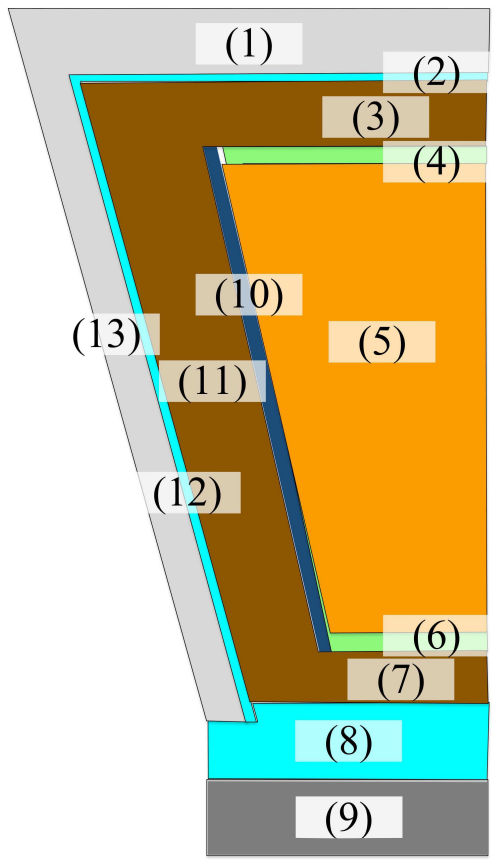

(a)

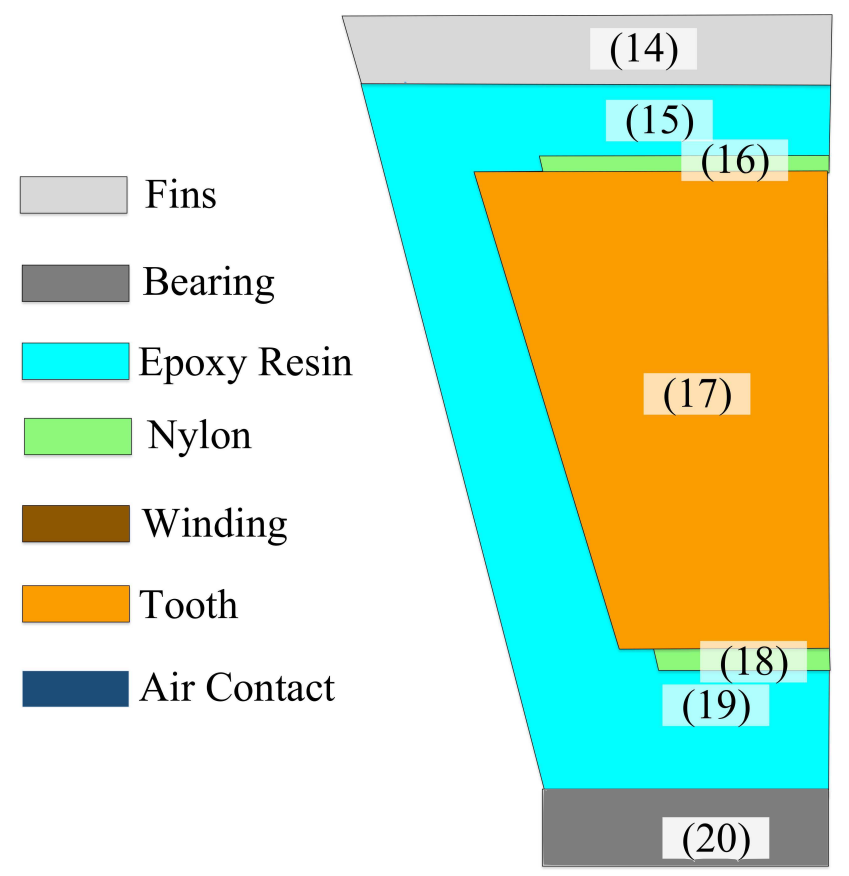

(b)

Figure 6. Regions of stator modeled part. (a) Section I at the center of the tooth; (b) Section II at the center of the tooth tips.

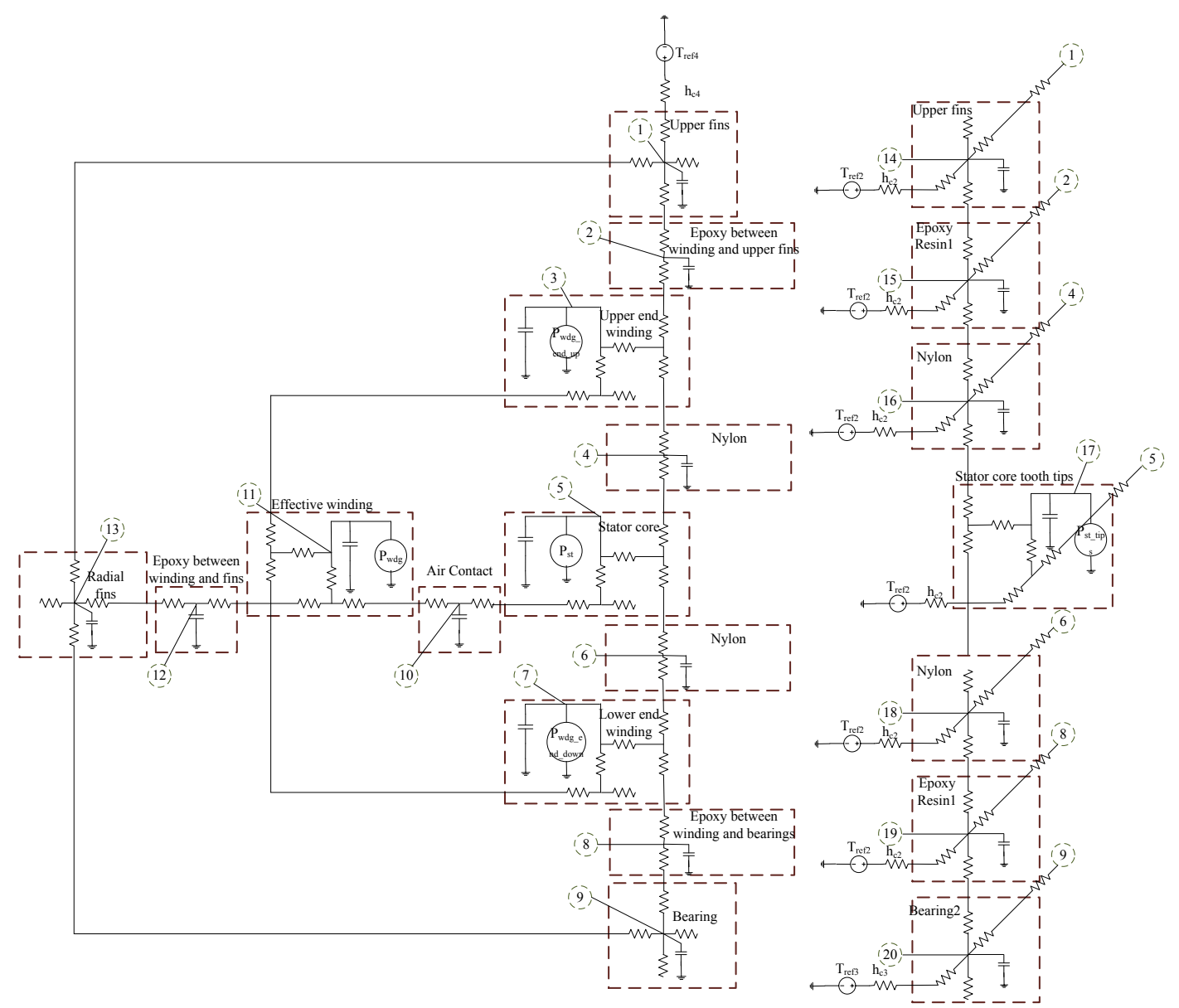

Figure 7. Lumped parameter thermal network (LPTN) of the stator. 


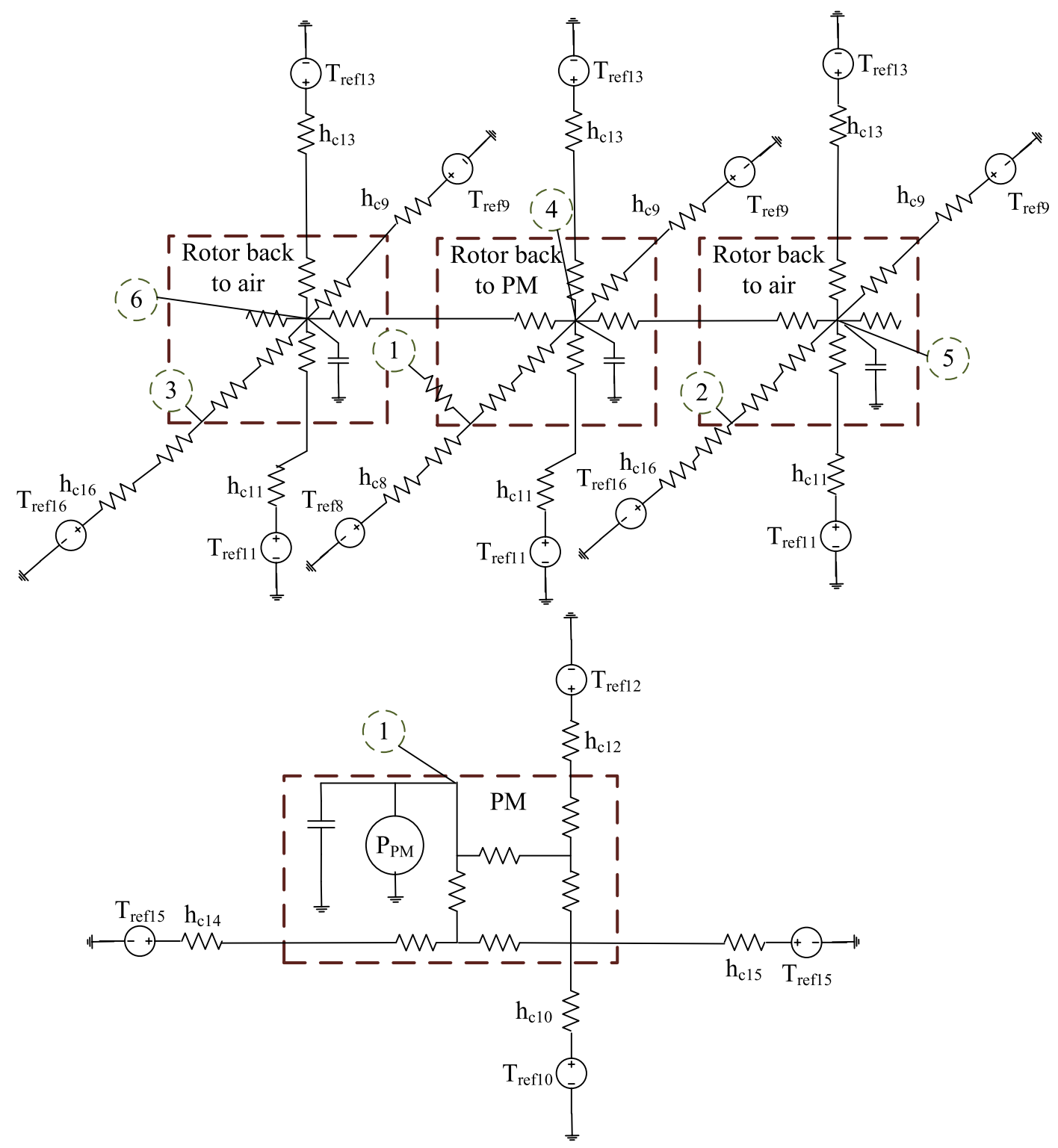

Figure 8. LPTN of the rotor.

\subsection{Solution of the LPTN}

The model is solved in a time stepping manner. The temperature at each sample time is calculated using:

$$
T_{n}=\left(G+\frac{C}{\triangle t}\right)^{-1}\left(P_{\text {loss }}+T R_{r e f}\right)+C \frac{T_{o}}{\triangle t}
$$

where $T_{n}$ is the temperature at sample number $n, \triangle t$ is the sampling time interval, $T R_{\text {ref }}$ is the reference temperature at each node divided by the resistance $R_{d, m}$ connected to this node, $G$ is the thermal conductance matrix, $P_{\text {loss }}$ is the power losses vector, $C$ is the thermal capacitance matrix of the machine, and $T_{o}$ is the temperature at sample number $n-1$.

The thermal conductance matrix $G$ is constructed as: 


$$
G=\left|\begin{array}{cccc}
\sum_{i=1, . .}^{m} \frac{1}{R_{1, i}} & -\frac{1}{R_{1,2}} & \cdots & -\frac{1}{R_{1, m}} \\
-\frac{1}{R_{2,1}} & \sum_{i=1, . .}^{m} \frac{1}{R_{2, i}} & \cdots & -\frac{1}{R_{2, m}} \\
\vdots & \vdots & \ddots & \vdots \\
-\frac{1}{R_{m, 1}} & -\frac{1}{R_{m, 2}} & \cdots & \sum_{i=1, . .}^{m} \frac{1}{R_{m, i}}
\end{array}\right|,
$$

where $m$ is the number of nodes in each matrix, and $R_{1, n}$ is the connecting resistance between each node $n$ and node number one.

The thermal capacitance matrix equals:

$$
C=\left|\begin{array}{cccc}
C_{1} & 0 & \ldots & 0 \\
0 & C_{2} & \ldots & 0 \\
\vdots & \vdots & \ddots & \vdots \\
0 & 0 & \ldots & C_{m}
\end{array}\right|
$$

The power losses vector $P_{\text {loss }}$ :

$$
P_{\text {loss }}=\left|\begin{array}{c}
P_{1} \\
P_{2} \\
\vdots \\
P_{m}
\end{array}\right|
$$

where $P_{m}$ corresponds to the power losses at node $m$ if it exists.

$$
T R_{r e f}=\left|\begin{array}{cc}
\sum_{d=1, . .} & \frac{T_{r e f_{d, 1}}}{R_{d, 1}} \\
\sum_{d=1, . .} \frac{T_{r e f_{d, 2}}}{R_{d, 2}} & \vdots \\
\sum_{d=1, . .} & \frac{T_{r e f_{d, m}}}{R_{d, m}}
\end{array}\right|
$$

The stator and rotor matrices are solved at each time step. However, the reference temperatures $T_{r e f}$ used in Equation (20) are dependent on the rotor and stator temperatures, therefore, at each time step the solution is iterated with updated values of the rotor and stator temperatures until the stabilization of both.

\section{3D FEM Thermal Model}

A 3D FEM model is developed and solved. The model considers the same boundary conditions as described in Section 2. These boundary conditions are convective heat transfer for surfaces exposed to convection and thermal insulation for surfaces parallel to the cutting plane due to thermal periodicity. The heat flow equation solved by the FEM is:

$$
\rho_{j} C_{p, j} \frac{\partial T}{\partial t}+\nabla \cdot\left(-k_{j} \nabla T\right)=q_{j}
$$

where $\rho_{j}$ is the density of material $j, C_{p, j}$ is the heat capacity of material $j$, and $k_{j}$ is the thermal conductivity of material $j$. In this FEM model, a heat generation of $1.667 \mathrm{~W}$, calculated using Equation (1), is assigned to the copper part. This value corresponds to a $100 \mathrm{~W}$ total copper loss, which is the same value as in the experimental work. Additionally, $0.25 \mathrm{~W}$ of heat generation 
is assigned to the PM to account for a $4 \mathrm{~W}$ total mechanical losses. The properties of the different materials used in the YASA AFPMSM machine prototype are in Table 1.

Table 1. Material properties.

\begin{tabular}{lccr}
\hline Material & $\boldsymbol{K}(\mathrm{W} / \mathrm{mK})$ & $C_{\boldsymbol{p}}(\mathrm{J} / \mathbf{k g K})$ & $\boldsymbol{\rho}\left(\mathbf{k g} / \mathbf{m}^{\mathbf{3}}\right)$ \\
\hline copper & 385 & 392 & 8890 \\
aluminum & 167 & 896 & 2712 \\
epoxy & 0.4 & 600 & 1540 \\
nylon & 0.25 & 1600 & 1140 \\
Nd-Fe-B & 9 & 500 & 7500 \\
\hline
\end{tabular}

The spatial distribution of the temperature of both stator and rotor parts is shown in Figure 9. This FEM model takes around $30 \mathrm{~min}$ to solve.

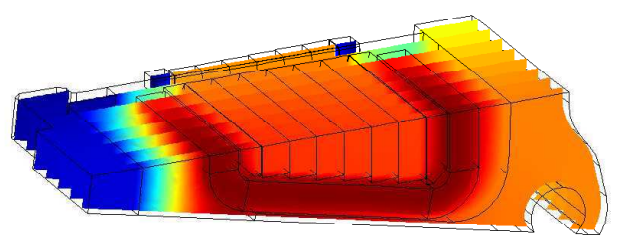

(a)

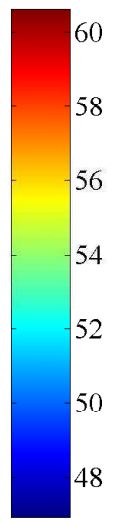

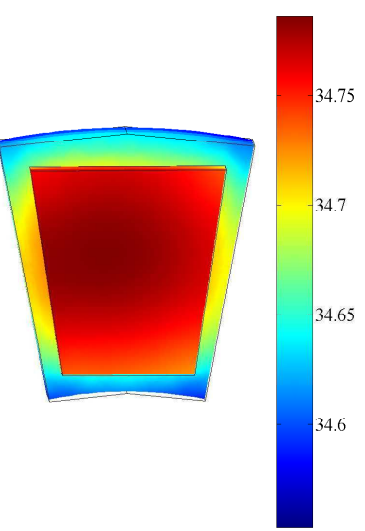

(b)

Figure 9. Spatial temperature distribution in degrees Celsius: (a) Stator; (b) Rotor.

\section{Experimental Setup and Results}

Measurements were carried out using the setup shown in Figure 10 to validate the LPTN model of the YASA machine. In the setup, the $4 \mathrm{~kW}$ YASA machine was coupled to an induction machine of $7.5 \mathrm{~kW}$ rated power, $3000 \mathrm{rpm}$ rated speed. The induction machine was used as a prime mover, and it was powered by a commercial drive. The induction motor speed set-points were provided to the drive by a dSPACE 1104 platform. The YASA machine geometrical parameters are presented in Table 2 . The experimental setup model input parameters are in Table 3.

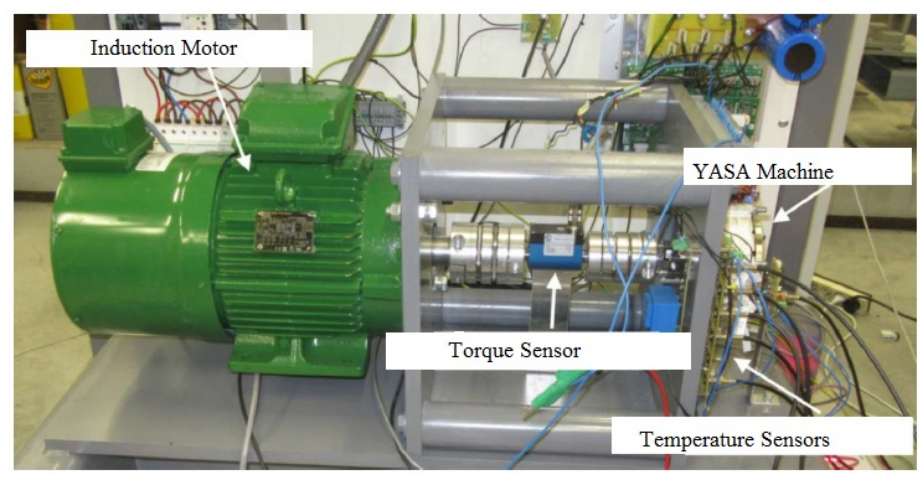

Figure 10. Experimental setup. 
Table 2. YASA geometrical parameters.

\begin{tabular}{lcc}
\hline Parameter & Value & Unit \\
\hline number of poles & 16 & - \\
teeth number & 15 & - \\
outer diameter housing & 195 & $\mathrm{~mm}$ \\
outer diameter active & 148 & $\mathrm{~mm}$ \\
PM thickness & 4 & $\mathrm{~mm}$ \\
rotor outer radius & 74 & $\mathrm{~mm}$ \\
slot width & 11 & $\mathrm{~mm}$ \\
\hline
\end{tabular}

Table 3. Experimental model input parameters.

\begin{tabular}{lcc}
\hline Parameter & Value & Unit \\
\hline air gap size ratio $(\mathrm{G})$ & 0.0135 & - \\
PM thickness ratio $(\mathrm{L})$ & 0.054 & - \\
PM angle ratio $\left(\alpha_{m}\right)$ & 0.8 & - \\
rotor speed & 1000 & $\mathrm{rpm}$ \\
\hline
\end{tabular}

A well-known heat source is required to validate the model, as well as its precise position; therefore, the actual Nd-Fe-B magnets were replaced by aluminum trapezoidal dummy PMs to avoid magnet losses. The windings were excited by a fixed DC current to get controlled losses and to eliminate the stator core losses. The mechanical losses are calculated using equations in [24]. The mechanical losses are lumped and injected in the PM node in the rotor LPTN model. The mechanical losses are bearing losses and windage losses. They are also validated using torque measurement and dummy magnets with different shapes. Evidently, the windage losses depend on the magnet shape parameters Figure $4\left(\alpha_{m}, L\right)$.

The stator core $T_{\text {core }}$ and winding $T_{\text {wind }}$ temperatures were measured by embedding a platinum resistance thermometer (PT100) inside them while the PM temperature $T_{p m}$ was measured by an infrared temperature sensor ZTP-135SR. The sensors output was sampled every $5 \mathrm{~s}$ for $110 \mathrm{~min}$.

During the experiment, the prime mover was rotated at $1000 \mathrm{rpm}$ and a fixed DC current was injected to get $100 \mathrm{~W}$ losses in the copper windings. The winding, core, and PM temperatures variation with time are shown in Figure 11.

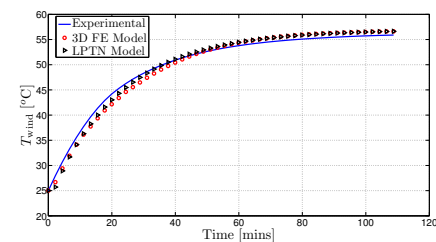

(a)

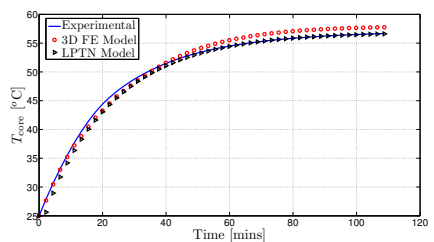

(b)

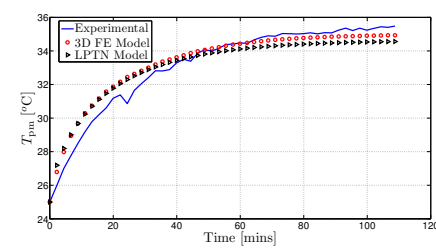

(c)

Figure 11. Machine (a) winding temperature; (b) core temperature; (c) PM temperature. FE: finite element.

It can be seen that the results are in a good agreement with the experimental outcome in both transient and steady state. Table 4 summarizes the steady state temperatures for the winding, stator core, and PM for experimental, FEM, and LPTN model. The relative error in the winding temperature was $0.9 \%$. On the other hand, the relative error in the core temperature was $0 \%$ and in the PM temperature it was $-2.24 \%$. It is also worth mentioning that the model took around $1 \mathrm{~s}$ to be solved, which is a small time that allows for rapid calculation of the machine temperatures and use in further thermal studies on the YASA AFPMSM machine. 
Table 4. Steady state temperatures at $1000 \mathrm{rpm}$.

\begin{tabular}{lccccc}
\hline & Experimental & FEM & LPTN & \% $_{\text {Error }}^{\text {LPTN }}$ & \% Error $_{\text {FEM }}$ \\
\hline$T_{\text {wind }}$ & 56.029 & 56.529 & 56.529 & 0.9 & 0.9 \\
$T_{\text {core }}$ & 56.68 & 57.38 & 56.68 & 0 & 1.23 \\
$T_{P M}$ & 35.582 & 35.18 & 34.782 & -2.24 & -1.12 \\
\hline
\end{tabular}

\section{Model Validation at Different Parameters}

The model was validated at different parameters. These parameters included the air gap size ratio $G, \mathrm{PM}$ span ratio $\alpha_{m}$, PM thickness ratio $L$, and rotor speed. These comparisons give more details on the effect of these parameters on the temperature rise inside the machine. In each parameter study, all other parameters were kept fixed at the values in Table 3.

\subsection{Effect of $\alpha_{m}$}

Two values of $\alpha_{m}$ of 0.7 and 0.9 were studied. The Results are shown in Figure 12. The LPTN is in a good agreement with the FEM results at both values of $\alpha_{m}$. The maximum relative difference between FEM and LPTN in any of the temperatures did not exceed $1.3 \%$. The temperature has a direct relation with the PM span ratio. As the PM span ratio increases the air channel area decreases, and less air flows inside these channels, leading to lesser heat evacuation. Consequently, the temperature rises.

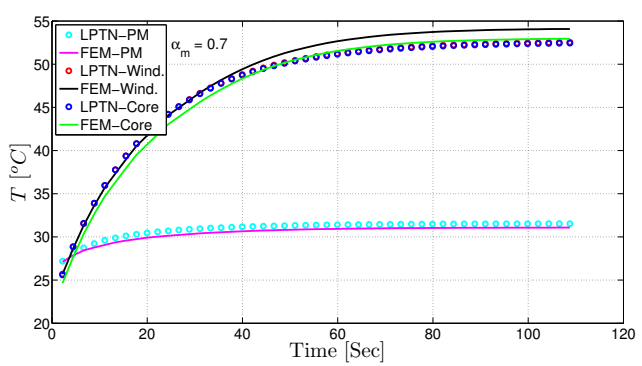

(a)

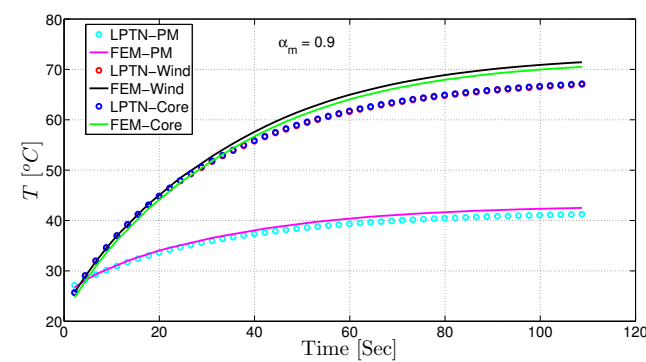

(b)

Figure 12. Machine temperature at (a) $\alpha_{m}=0.7 ;$ (b) $\alpha_{m}=0.9$.

\subsection{Effect of $L$}

Different values of PM thickness ratio of 0.03 and 0.07 were investigated. Figure 13 shows the results at $L=0.03$ and 0.07 . The results are in a good agreement, with less than $1 \%$ difference in any of the temperatures. The results indicate that when $L$ increases the temperature decreases, and vice versa.

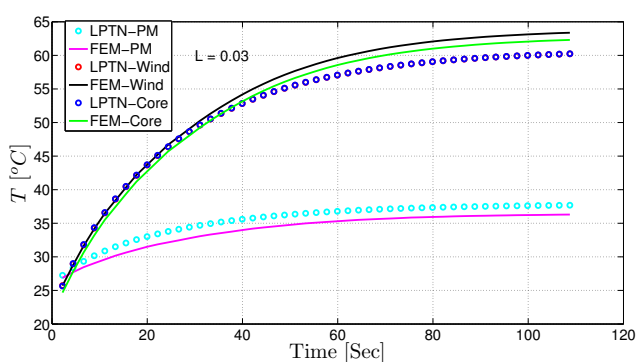

(a)

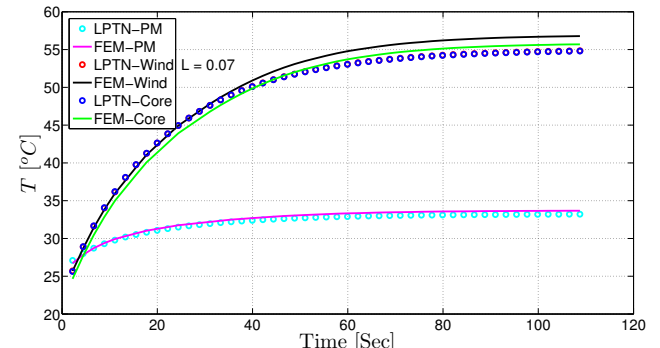

(b)

Figure 13. Machine temperature at (a) $L=0.03 ;(\mathbf{b}) L=0.07$. 


\subsection{Effect of $G$}

The influence of the air gap size ratio was investigated at 0.0067 and 0.0337 . These values correspond to $0.5 \mathrm{~mm}$ and $2.5 \mathrm{~mm}$ air gap thickness, respectively. The model is in good agreement with $1.25 \%$ maximum relative difference. Figure 14 shows the results. It can be seen that the temperature increased at both values of air gap length, because the heat transfer is maximum at some air gap length, and the heat transfer rate decreases below and above that value $[18,19]$.

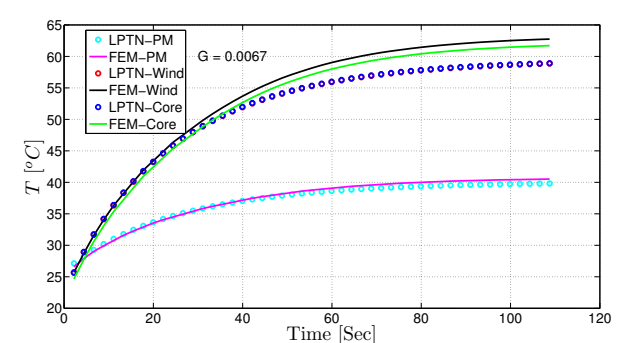

(a)

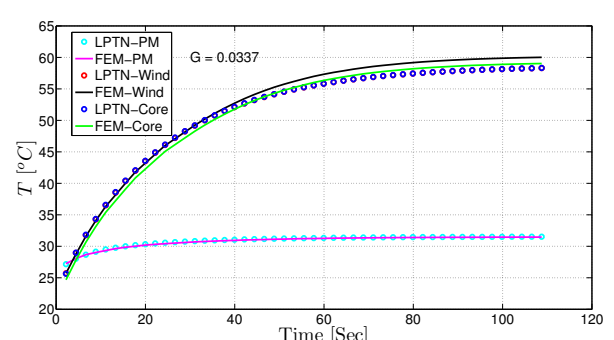

(b)

Figure 14. Machine temperature at (a) $G=0.0067 ;(\mathbf{b}) G=0.0337$.

\subsection{Effect of Rotor Speed}

The results at rotor speed of $2000 \mathrm{rpm}$ are shown in Figure 15. The results are in a good match also with $0.5 \%$ maximum relative difference. The temperature decreases when the speed increases due to higher Nusselt numbers and hence higher convection coefficients.

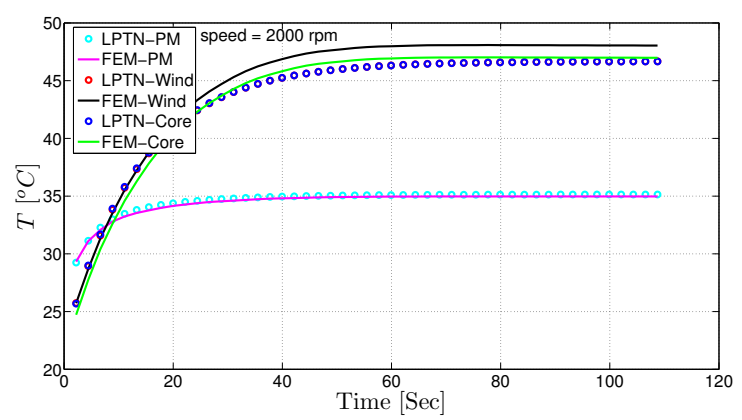

Figure 15. Machine temperature at speed $=2000 \mathrm{rpm}$.

\section{Conclusions}

In this paper, a 3D transient LPTN model is developed for the YASA axial flux permanent magnet synchronous machine. The model considers the innovative cooling through air channels between magnets. The model takes only $1 \mathrm{~s}$ to solve for the temperature value in different parts of the machine: the copper winding, the stator core, PM, and other parts of the machine. The model is validated by measurements on an experimental work and by FEM results at different values of air gap thickness, rotor speed, and geometrical parameters of the PM. The results correspond very well in both transient and steady state. The model is very fast and can be used for further thermal design of the machine.

Acknowledgments: This research was done in the framework of the Hipercool project from Flanders Make. 
Author Contributions: Each of the authors contributed to the preparation of this research paper. Abdalla Hussein Mohamed enhanced the accuracy of the initial model, made the parametric validation, and wrote the paper. Ahmed Hemeida developed the initial version of the model and contributed to the experimental work. Alireza Rashekh contributed to the experimental work. Hendrik Vansompel initialized the experimental setup. Antero Arkkio revised the paper. Peter Sergeant revised the manuscript substantially.

Conflicts of Interest: The authors declare no conflict of interest.

\section{References}

1. Du-Bar, C. Design of an Axial Flux Machine for an in-Wheel Motor Application; Chalmers Reproservice: Göteborg, Sweden, 2011.

2. Tiegna, H.; Bellara, A.; Amara, Y.; Barakat, G. Analytical modeling of the open-circuit magnetic field in axial flux permanent-magnet machines with semi-closed slots. IEEE Trans. Magn. 2012, 48, 1212-1226.

3. Vansompel, H.; Sergeant, P.; Dupré, L. A multilayer 2-D-2-D coupled model for eddy current calculation in the rotor of an axial-flux PM machine. IEEE Trans. Energy Convers. 2012, 27, 784-791.

4. Hemeida, A.; Sergeant, P. Analytical modeling of surface PMSM using a combined solution of Maxwell's equations and Magnetic Equivalent Circuit (MEC). IEEE Trans. Magn. 2014, 50, 7027913.

5. Hemeida, A.; Sergeant, P. Analytical modeling of eddy current losses in Axial Flux PMSM using resistance network. In Proceedings of the 2014 International Conference on Electrical Machines (ICEM), Berlin, Germany, 2-5 September 2014; pp. 2688-2694.

6. Hemeida, A.; Sergeant, P.; Vansompel, H. Comparison of Methods for Permanent Magnet Eddy Current Loss Computations With and Without Reaction Field Considerations in Axial Flux PMSM. IEEE Trans. Magn. 2015, 9464, doi:10.1109/TMAG.2015.2431222.

7. Hemeida, A.; Hannon, B.; Sergeant, P. Comparison of three analytical methods for the precise calculation of cogging torque and torque ripple in PM machines. Math. Probl. Eng. 2016, 2016, 2171547.

8. Mueller, M.; McDonald, A.; Macpherson, D. Structural analysis of low-speed axial-flux permanent-magnet machines. IEE Proc. Electr. Power Appl. 2005, 152, 1417.

9. Vun, S.T.; McCulloch, M.D. Optimal Design Method for Large-Scale YASA Machines. IEEE Trans. Energy Convers. 2015, 30, 900-907.

10. Kumar, S.; Lipo, T.A.; Kwon, B.I. A 32000 r/min Axial Flux Permanent Magnet Machine for Energy Storage With Mechanical Stress Analysis. IEEE Trans. Magn. 2016, 52, doi:10.1109/TMAG.2015.2512939.

11. Hemeida, A.; Taha, M.; Abdallh, A.; Vansompel, H.; Dupré, L.; Sergeant, P. Applicability of Fractional Slot Axial Flux Permanent Magnet Synchronous Machines in the Field Weakening Region. IEEE Trans. Energy Convers. 2016, 32, 111-121.

12. Jiang, W.; Member, S.; Jahns, T.M. Coupled Electromagnetic-Thermal Analysis of Electric Machines Including Transient Operation Based on Finite-Element Techniques. In Proceedings of the 2013 IEEE Energy Conversion Congress and Exposition (ECCE), Denver, CO, USA, 15-19 September 2013; pp. 1880-1889.

13. Tan, Z.; Song, X.G.; Ji, B.; Liu, Z.; Ma, J.E.; Cao, W.P. 3D thermal analysis of a permanent magnet motor with cooling fans. J. Zhejiang Univ. Sci. A 2015, 16, 616-621.

14. Polikarpova, M.; Ponomarev, P.; Lindh, P.; Petrov, I.; Jara, W.; Naumanen, V.; Tapia, J.A.; Pyrhonen, J. Hybrid Cooling Method of Axial-Flux Permanent-Magnet Machines for Vehicle Applications. IEEE Trans. Ind. Electron. 2015, 62, 7382-7390.

15. Marignetti, F.; Delli Colli, V.; Coia, Y. Design of Axial Flux PM Synchronous Machines Through 3-D Coupled Electromagnetic Thermal and Fluid-Dynamical Finite-Element Analysis. IEEE Trans. Ind. Electron. 2008, $55,3591-3601$.

16. Marignetti, F.; Colli, V. Thermal Analysis of an Axial Flux Permanent-Magnet Synchronous Machine. IEEE Trans. Magn. 2009, 45, 2970-2975.

17. Howey, D.A.; Holmes, A.S.; Pullen, K.R. Measurement and CFD Prediction of Heat Transfer in Air-Cooled Disc-Type Electrical Machines. IEEE Trans. Ind. Appl. 2011, 47, 1716-1723.

18. Rasekh, A.; Sergeant, P.; Vierendeels, J. Convective heat transfer prediction in disk-type electrical machines. Appl. Therm. Eng. 2015, 91, 778-790.

19. Rasekh, A.; Sergeant, P.; Vierendeels, J. Fully predictive heat transfer coefficient modeling of an axial flux permanent magnet synchronous machine with geometrical parameters of the magnets. Appl. Therm. Eng. 2017, 110, 1343-1357. 
20. Sahin, F. Design and Development of a High-Speed Axial-Flux Permanent-Magnet Machine Design and Development of a High-Speed Axial-Flux Permanent-Magnet Machine. In Proceedings of the Conference Record of the 2001 IEEE Thirty-Sixth IAS Annual Meeting, Industry Applications Conference, Chicago, IL, USA, 30 September-4 October 2001.

21. Vansompel, H.; Rasekh, A.; Hemeida, A.; Vierendeels, J.; Sergeant, P. Coupled Electromagnetic and Thermal Analysis of an Axial Flux PM Machine. IEEE Trans. Magn. 2015, 51, doi:10.1109/TMAG.2015.2433392.

22. Rostami, N.; Feyzi, M.R.; Pyrhonen, J.; Parviainen, A.; Niemela, M. Lumped-Parameter Thermal Model for Axial Flux Permanent Magnet Machines. IEEE Trans. Magn. 2013, 49, 1178-1184.

23. Lim, C.; Bumby, J.; Dominy, R.; Ingram, G.; Mahkamov, K.; Brown, N.; Mebarki, A.; Shanel, M. 2-D lumped-parameter thermal modelling of axial flux permanent magnet generators. In Proceedings of the 18th International Conference on Electrical Machines (ICEM 2008), Vilamoura, Portugal, 6-9 September 2008; pp. 1-6.

24. Rasekh, A.; Sergeant, P.; Vierendeels, J. Development of correlations for windage power losses modeling in an axial flux permanent magnet synchronous machine with geometrical features of the magnets. Energies 2016, 9, 1009.

25. Mellor, P.; Roberts, D.; Turner, D. Lumped parameter thermal model for electrical machines of TEFC design. IEE Proc. B Electr. Power Appl. 1991, 138, 205-218.

26. Kuehbacher, D.; Kelleter, A.; Gerling, D. An improved approach for transient thermal modeling using lumped parameter networks. In Proceedings of the 2013 IEEE International Electric Machines \& Drives Conference (IEMDC), Chicago, IL, USA, 12-15 May 2013; pp. 824-831.

27. Kylander, G. Thermal Modelling of Small Cage Induction Motors. Ph.D. Thesis, School of Electrical and Computer Engineering, Chalmers University of Technology, Göteborg, Sweden, 1995.

(C) 2018 by the authors. Licensee MDPI, Basel, Switzerland. This article is an open access article distributed under the terms and conditions of the Creative Commons Attribution (CC BY) license (http:/ / creativecommons.org/licenses/by/4.0/). 